\title{
Age differences in night-time metabolic rate and body temperature in a small passerine
}

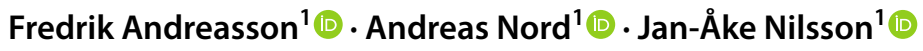

Received: 12 November 2019 / Revised: 31 January 2020 / Accepted: 7 February 2020 / Published online: 24 February 2020

(c) The Author(s) 2020

\begin{abstract}
Spending the winter in northern climes with short days and cold ambient temperatures $\left(T_{\mathrm{a}}\right)$ can be energetically challenging for small birds that have high metabolic and heat loss rates. Hence, maintaining body temperature $\left(T_{\mathrm{b}}\right)$ in $T_{\mathrm{a}}$ below thermoneutrality can be energetically costly for a small bird. We still know little about how increased heat production below thermoneutrality affects the level at which $T_{\mathrm{b}}$ is maintained, and if these patterns are age specific. To test this, we measured subcutaneous body temperature $\left(T_{\mathrm{s}}\right)$ and resting metabolic rate (RMR) simultaneously in blue tits (Cyanistes caeruleus) during winter nights in $T_{\mathrm{a}}$ 's ranging from 25 to $-15^{\circ} \mathrm{C}$. RMR increased below the lower critical temperature (LCT, estimated at $14{ }^{\circ} \mathrm{C}$ ) and was $6 \%$ higher in young (birds in their first winter) compared to old birds (birds in their second winter or older). The higher RMR was also mirrored in higher $T_{\mathrm{s}}$ and thermal conductance $(C)$ in young birds, which we suggest could be caused by age differences in plumage quality, likely driven by time constraints during moult. Reduction in nightly predicted $T_{\mathrm{b}}$ was modest and increased again at the coldest ambient temperatures, suggesting that either heat retention or heat production (or both) improved when $T_{\mathrm{a}}$ reached levels which are cold by the standards of birds in our population. Our results show that levels of heat production and $T_{\mathrm{b}}$ can be age specific. Further studies should address age-specific differences on quality, structure, and thermal conductivity of plumage more explicitly, to investigate the role of variation in insulation in age-linked metabolic phenotypes.
\end{abstract}

Keywords Thermoregulation $\cdot$ Hypothermia $\cdot$ Age effects $\cdot$ Thermogenesis $\cdot$ Bird $\cdot$ Metabolic rate

\section{Introduction}

Animals that overwinter at northern latitudes face several energetic challenges. It is often cold, days are short, and food supply can be scarce. Such conditions are especially challenging for small birds that have high surface area to volume ratio (which increases heat loss rate), high massspecific metabolic rate, and limited capacity to store energy as fat (e.g., Haftorn 1992). Thus, a small bird in winter needs to minimize energy expenditure while simultaneously

Communicated by G. Heldmaier.

Electronic supplementary material The online version of this article (https://doi.org/10.1007/s00360-020-01266-5) contains supplementary material, which is available to authorized users.

Fredrik Andreasson

fredrik.andreasson@biol.lu.se

1 Department of Biology, Section for Evolutionary Ecology, Lund University, Lund, Sweden maximizing energy intake and heat production capacity. Several behavioral adaptations, such as communal roosting (DuPlessis and Williams 1994), choosing optimal roosting sites (Elkins 2004), and ptiloerection (Hill et al. 1980; Hohtola et al. 1980) reduces heat loss and energy expenditure in thermally challenging environments. Physiologically, one way to conserve energy is to reduce body temperature, $T_{\mathrm{b}}$, during resting periods, which is typically referred to as shallow hypothermia, rest-phase hypothermia or night-time hypothermia (McKechnie and Lovegrove 2002). Hypothermia can amount to significant energy savings (Reinertsen and Haftorn 1986; Cooper and Gessaman 2005) and is predicted to substantially increase winter survival even when energy savings are moderate (Brodin et al. 2017). Despite the potential energetic savings and benefits to winter survival, birds seem to attenuate or avoid nightly hypothermia in milder ambient temperatures $\left(T_{\mathrm{a}}\right)$, when food is plentiful and when body condition is high (Reinertsen and Haftorn 1986; Dolby et al. 2004; Nord et al. 2009, 2011). This indicates that there are costs associated with the use of 
hypothermia, e.g., impaired quality of sleep (Mueller et al. 2012), impaired immune function (Nord et al. 2013; SköldChiriac et al. 2015), and increased predation risk (Laurila and Hohtola 2005; Carr and Lima 2013; Andreasson et al. 2019).

The energy expenditure of any resting bird or mammal (assuming a post-absorptive state) is a function of its metabolic rate which in turn is related to its $T_{\mathrm{b}}$ and thermal conductance, $C$. When $T_{\mathrm{a}}$ falls below the lower critical temperature (LCT), i.e. below the thermoneutral zone (TNZ) where basal heat metabolism is enough to maintain preferred $T_{\mathrm{b}}$, heat must be produced to defend $T_{\mathrm{b}}$. In birds, heat is believed to be produced mainly by shivering thermogenesis (Marsh and Dawson 1989; Hohtola 2004), although there is evidence for non-shivering thermogenesis in a few species (Duchamp et al. 1992; Duchamp and Barré 1993; Teulier et al. 2010). The thermal conductivity of the plumage has a large effect on total conductance. This probably explains why plumage insulation changes as part of a seasonal acclimatization to winter conditions (e.g., Dawson and Carey 1976; Swanson 1991; Cooper 2002) and is more developed in birds residing further north (Pap et al. 2017; Osvath et al. 2018). Yet, plumage quality is still a somewhat static trait that is mainly modulated during moult, and so not amenable for variation on a night-to-night basis. Metabolic rate and nocturnal hypothermia, on the other hand, are open for dynamic and strategic changes that potentially depend on $T_{\mathrm{a}}$ and internal states such as size, age and nutritional state. However, although several studies have investigated nocturnal hypothermia in small, northern passerines (e.g., Palmgren 1944; Udvardy 1955; Steen 1958; Haftorn 1992; Hill et al. 1980; Reinertsen and Haftorn 1983; Reinertsen and Haftorn 1986) and the proximate mechanisms that determine the depth and use of hypothermia (i.e., ambient conditions, body condition/reserves, food availability and predation risk; Reinertsen and Haftorn 1986; Dolby et al. 2004; Nord et al. 2009, 2011; Andreasson et al. 2019), we still know relatively little about how increased heat production below thermoneutrality actually affects at which level $T_{\mathrm{b}}$ is maintained. Some studies have measured both metabolic rate and $T_{\mathrm{b}}$ continuously (black-capped chickadees (Poecile atricapillus): Chaplin 1976; Grossman and West 1977; willow tits (Poecile montanus): Reinertsen and Haftorn 1983; Reinertsen and Haftorn 1984; greenfinches (Chloris chloris): Saarela et al. 1995) in $T_{\mathrm{a}}$ below thermoneutrality. Those studies have provided valuable information on annual and circadian variation in $T_{\mathrm{b}}$ and metabolic rate and their relationship with food availability, $T_{\mathrm{a}}$ and shivering. However, to the best of our knowledge, the effect of state variables, such as age, on $T_{\mathrm{b}}$ and metabolic rate in "the little bird in winter" (sensu Brodin 2007) is yet to be tested.

Age is a particularly interesting state variable as young and old birds may differ in both heat producing and heat retaining capacity, likely as a consequence of different plumage properties, and age-related differences in metabolic rate and $T_{\mathrm{b}}$. Juveniles need to finish growing and attain a certain body condition before energy-consuming moult can begin (Ginn and Melville 1983; Vágási et al. 2012), while adult blue tits (Cyanistes caeruleus) can commence their complete post-nuptial moult earlier (sometimes already while feeding their chicks: Svensson and Nilsson 1997). Thus, a more time-constrained, delayed moult of juveniles could lead to plumage of inferior insulating capacity (Nilsson and Svensson 1996). Moreover, great tits (Parus major) from a northerly population, being more time constrained during moult due to shorter day lengths, produce contour feathers that are likely of inferior insulating capacity compared to birds from a more southern population (shorter, and with a lower proportion of plumulaceous barbs: Broggi et al. 2011). This pattern is also clear in Svalbard ptarmigan (Lagopus muta hyperborea) where young birds have a higher resting metabolic rate, RMR, and $C$ compared to older conspecifics in winter after post-juvenile moult (where they are time constrained), but not the following summer where onset of moult is the same for both age groups (Nord and Folkow 2018). In addition, young blue tits keep a higher $T_{\mathrm{b}}$ in cold ambient temperatures when faced with a higher perceived predation risk compared to older birds (Andreasson et al. 2019), which would require either amplified heat production, reduced heat loss or both. Thus, physiological and behavioral age-related differences could potentially shape the relation between metabolic rate and $T_{\mathrm{b}}$ differently during a cold winter night.

Our aim was to study patterns of $T_{\mathrm{b}}$ regulation and metabolic rate in the "little bird in winter", with a specific focus on potential differences between young and old birds. Given the potential age-related variation in both plumage quality and metabolic capacity, we predicted that LCT and metabolic rate below LCT would be higher in birds that were in their first winter (young) compared to those that had experienced at least one winter before (old). To test this, we measured metabolic rate and nightly subcutaneous body temperature, $T_{\mathrm{s}}$, simultaneously during sliding cold exposure $\left(+25\right.$ to $-15{ }^{\circ} \mathrm{C}$ ) in young and old, wild, blue tits in winter.

\section{Methods}

\section{Instrumentation for $T_{\mathrm{b}}$ measurement}

The blue tit is a small (11-13 g), hole-nesting passerine with a high mass-specific metabolic rate. In southern Sweden, the blue tits that remain resident over winter (Smith and Nilsson 1987) and routinely use nest boxes for non-communal night roosts, making them well suited for this kind of study. All birds were free-living blue tits captured when roosting 
in nest boxes around Lake Krankesjön, $20 \mathrm{~km}$ east of Lund in southern Sweden $\left(55^{\circ} 42^{\prime} \mathrm{N}, 13^{\circ} 28^{\prime} \mathrm{E}\right)$ from $23 \mathrm{Nov}$ 2017 to 30 Jan 2018 . When a roosting blue tit was found, we weighed $( \pm 0.1 \mathrm{~g})$, ringed, and aged the bird based on plumage characteristics (Svensson 1992) and also measured tarsus- $( \pm 0.1 \mathrm{~mm})$ and wing length $( \pm 0.5 \mathrm{~mm})$. Then, we implanted a temperature-sensitive passive integrated transponder tag (PIT tag; BioTherm13-Biomark, Boise ID, USA; height: $13.0 \mathrm{~mm}$; diameter: $2.1 \mathrm{~mm}$ ) subcutaneously in the neck under aseptic conditions (following Nord et al. 2013; Sköld-Chiriac et al. 2015). The incision hole was sealed using cyanoacrylate (Loctite Power Easy Gel, Henkel AG \& Company, Düsseldorf, Germany) before the bird was returned to the nest box. In total, 65 birds were implanted. Three additional birds that were already tagged during the breeding season in 2017 were also used in this study.

\section{Metabolic rate measurements}

PIT-tagged birds were recaptured when roosting in nest boxes just after sunset $32 \pm 14( \pm \mathrm{SD})$ days after instrumentation (range 6-78 days). Two birds per night were brought to Lund University for measurement of metabolic rate and $T_{\mathrm{b}}$ starting $1.6 \pm 0.4 \mathrm{~h}$ after sunset (mean start time 17:57 GMT + 1) and lasting throughout the night $(1.2 \pm 0.4 \mathrm{~h}$ before sunrise; mean end time 06:58 GMT +1 ), after which the birds were returned to the nest boxes in which they had been caught. All measurements took place between $19 \mathrm{Dec}$ 2017 and 15 Feb 2018.

We put birds individually in cylindrical $0.6 \mathrm{~L}$, hermetic, polyvinyl chloride (PVC) chambers placed in a dark, temperature-controlled cabinet (Weiss Technik WK3 C180, Reiskirchen, Germany). An identical chamber was left empty for baselining. Chamber temperature, $T_{\mathrm{a}}$, was measured continuously with a thermocouple (36 gauge, type T, copper-constantan) connected to a thermocouple meter (TC-2000, Sable Systems). The climate cabinet temperature changed in incremental steps of $5{ }^{\circ} \mathrm{C}$, so that birds were subjected to a temperature regime starting at $25^{\circ} \mathrm{C}$ in the evening and ending at $-15^{\circ} \mathrm{C}$ in the morning (standard order, $n=20$ ) or starting at $-15^{\circ} \mathrm{C}$ in the evening and ending at $20^{\circ} \mathrm{C}$ in the morning (reversed order, $n=10$ ). All birds were placed in the climate cabinet, set at the starting temperature of the program $\left(25^{\circ} \mathrm{C}\right.$ or $-15{ }^{\circ} \mathrm{C}$ ) for $80 \mathrm{~min}$ acclimation before data collection commenced. Each temperature step lasted $80 \mathrm{~min}$ and during this time each animals was measured for 20 min which was preceded and succeeded by $20 \mathrm{~min}$ of baselining via the empty chamber. Baseline gas concentrations were calculated as the mean of the last minute of baselining before and after each animal measurement. This protocol was adequate to obtain stable RMR and $T_{\mathrm{b}}$. Subcutaneous body temperature, $T_{\mathrm{s}}$, was measured each min by implanted PIT tags, and was recorded by a Biomark HPR Plus data logger (Biomark, Boise ID, USA) connected to an antenna placed directly beneath the metabolic chambers.

We pushed (mean flow \pm SD) $287 \pm 9 \mathrm{~mL} \mathrm{~min}^{-1}$ (STP) pressurized air (measured by a FlowBar- 8 multichannel mass flow meter, Sable Systems) over each channel. Effluent air was measured for relative humidity (RH-300, Sable Systems) before water vapor was removed by Drierite (W.A. Hammond Drierite Company, Xenia, OH) and the gas stream was analyzed sequentially for carbon dioxide (CA-10A, Sable Systems) and oxygen (FC-10A, Sable Systems). Gas concentrations, relative humidity, flow rate, and $T_{\mathrm{a}}$ were recorded every second, and were digitized by a UI2 data acquisition interface (Sable Systems). Switching between channels was achieved automatically using a RM8 multiplexer (V3, Sable Systems).

We calibrated the carbon dioxide analyzer using $100 \%$ $\mathrm{N}_{2}$ and $1 \% \mathrm{CO}_{2}$ in $\mathrm{N}_{2}$. The oxygen analyzer was calibrated using $100 \% \mathrm{~N}_{2}$ and incoming air $\left(20.95 \% \mathrm{O}_{2}\right)$. Calibration of the carbon dioxide analyzer, and zero calibration of the oxygen analyzer, was performed immediately before the start of the experiment. Span calibration of the oxygen analyzer was performed daily. In addition, we calibrated the oxygen analyzer using a gas of known $\mathrm{O}_{2}$ concentration $\left(20.4 \%\right.$, in $\left.\mathrm{N}_{2}\right)$ on three separate occasions during and directly after the measurement series. The RH meter had been factory calibrated shortly before the experiment started.

\section{Calculation of metabolic rate}

We calculated $\mathrm{O}_{2}$ consumption rate $\left(V_{\mathrm{O}_{2}}\right)$ in $\mathrm{mL} \mathrm{min}^{-1}$ following Eq. 10.6 in Lighton (2008):

$V_{\mathrm{O}_{2}}=f_{\mathrm{STPD}} \times \frac{\left(F_{I_{\mathrm{O}_{2}}}-F_{E_{\mathrm{O}_{2}}}\right)-F_{E_{\mathrm{O}_{2}}} \times\left(F_{E_{\mathrm{CO}_{2}}}-F_{I_{\mathrm{CO}_{2}}}\right)}{1-F_{E_{\mathrm{O}_{2}}}}$,

where $F_{I_{\mathrm{O}_{2}}}, F_{I_{\mathrm{CO}_{2}}}, F_{E_{\mathrm{O}_{2}}}, F_{E_{\mathrm{CO}_{2}}}$ are influent and effluent fractional concentrations of $\mathrm{O}_{2}$ and $\mathrm{CO}_{2}$, respectively, and $f_{\text {STPD }}$ is standard temperature and pressure, dry (STPD)-corrected flow rate $\left(\mathrm{mL} \mathrm{min}^{-1}\right)$ calculated by subtracting $f_{\mathrm{H}_{2} \mathrm{O}}$ (Eq. 2 following Nord and Folkow 2018) from standard temperature- and pressure-corrected flow, $f_{\mathrm{STP}}\left(\mathrm{mL} \mathrm{min}^{-1}\right)$, as measured by the flow meter. In Eq. 2, $T_{\text {gas }}$ is gas temperature, $\mathrm{RH}$ is relative humidity (here we used fixed values of $13.17625{ }^{\circ} \mathrm{C}$ and $8.60821 \%$ based on mean $T_{\text {gas }}$, and $\mathrm{RH}$ measured over a whole night (18:00-06:00 GMT + 1) on 21 Feb 2018) and BP is barometric pressure ( $\mathrm{mmHg}$ ) during the experimental night, measured at Malmö Airport, $22 \mathrm{~km}$ from Lund University (Swedish Meteorological and Hydrological Institute 2018, unpublished data) 
$f_{\mathrm{H}_{2} \mathrm{O}}=f_{\mathrm{STP}} \times \frac{(\mathrm{RH} / 100) \times 4.588 \times 10^{\left(7.59 \times T_{\text {gas }}\right) /\left(240.73+T_{\text {gas }}\right)}}{\mathrm{BP}}$.

We converted oxygen consumption to energy consumption $(W)$ assuming an oxyjoule equivalence of $20 \mathrm{~J} \mathrm{~mL}^{-1}$ $\mathrm{O}_{2}$ (Kleiber 1961). Wet thermal conductance, $C\left(W^{\circ} \mathrm{C}^{-1}\right)$, was calculated following Aschoff (1981):

$C=\operatorname{RMR} /\left(T_{\mathrm{s}}-T_{\mathrm{a}}\right)$.

\section{Sample sizes}

All analyses of RMR, $C, T_{\mathrm{s}}$ and $T_{\mathrm{a}}$ were made on mean values per minute for each individual of the last $10 \mathrm{~min}$ in each temperature interval (to obtain the most stable readings). Thus, total sample size was data from 260 temperature intervals from 30 individuals (20 individuals with 9 temperature intervals-standard, 10 individuals with 8 temperature intervals-reversed). We wanted to exclude data that were indicative of either stress and/or activity. Since we did not record behavior, we excluded data where the standard deviation in oxygen consumption during the 10 min of measurement were $>2$ SD larger than the mean standard deviation $(n=11)$. One additional observation was excluded as the temperature profile clearly suggested substantial activity. Thus, final sample size was 248 observations based on 30 individuals (young: $n=16$, old: $n=14$ ). Due to technical malfunction, we were unable to record $T_{\mathrm{s}}$ for three of these observations.

\section{Predicted $\mathbf{T}_{\mathbf{b}}$}

To evaluate the relationship between $T_{\mathrm{s}}$ and cloacal temperature, $T_{\mathrm{c}}$, we measured these two parameters simultaneously in four birds, outside of the main experiment. The birds were placed in the metabolic chambers in the climate cabinet and subjected to the same temperature regime (reversed order from -15 to $20^{\circ} \mathrm{C}$ ) over the full night. $T_{\mathrm{s}}$ was recorded each minute as in the main experiment, and $T_{\mathrm{c}}$ was recorded each s by inserting a 36-gauge type $\mathrm{T}$ thermocouple attached to a thermocouple meter (TC-2000, Sable Systems) $12 \mathrm{~mm}$ through the cloaca. The thermocouple was fixed to two tail feathers using surgical tape. We excluded data from one bird where the thermocouple had been dislodged during the night. The three full profiles of $T_{\mathrm{s}}$ and $T_{\mathrm{c}}$ (see Fig. 1a for a representative example) were used to calculate mean difference $(\Delta T)$ between $T_{\mathrm{s}}$ and $T_{\mathrm{c}}$ at each temperature intervals (Fig. 1b). These temperaturespecific values were used to calculate predicted $T_{\mathrm{b}}$ for all experimental birds.

\section{Statistical analyses}

All statistical analyses were performed in $\mathrm{R}$ ver. 3.5.1 ( $\mathrm{R}$ Development Core Team 2018). To determine LCT, we used a mixed "broken-stick" model (lmer package: Bates et al. 2015) with RMR as the dependent variable with a variable break point (see Supporting Information for R code), $T_{\mathrm{a}}$ as a covariate and bird ID as a random factor. Two identical models were also fitted to estimate LCT in the two age groups.

We then used linear mixed models (lmer package) to evaluate the effect of age and $T_{\mathrm{a}}$ on RMR both below and above (overall) LCT, respectively. We also included the twoway interaction age $\times T_{\mathrm{a}}$. Bird ID was added as a random factor (random intercept for models above LCT and random intercept + slope for models below LCT). An identical model was also fitted for thermal conductance below LCT. To account for the effect of body mass on metabolic rate, we also ran these models with body mass as a covariate, avoiding the use of mass-specific indices (see Packard and Boardman 1999; Hayes 2001). Body mass was corrected for time of measurement, i.e. we calculated the body mass of the bird at the actual time of measurement assuming a linear decrease over time from evening to morning body mass. Mean $( \pm \mathrm{SD})$ evening and morning body mass was $12.1 \pm 0.9$ and $11.3 \pm 0.9 \mathrm{~g}$, respectively. Estimated regression lines and predicted values from these models are presented in text and figures as mass-adjusted RMR and massadjusted conductance.

For subcutaneous temperature, $T_{\mathrm{s}}$, and predicted body temperature, $T_{\mathrm{b}}$, we fitted similar models but with centered $T_{\mathrm{a}}$. In addition, we also added $T_{\mathrm{a}}^{2}$ and the interaction with age to account for the quadratic pattern.

All lmer models were fitted using restricted maximum likelihood (REML) and interactions with $p>0.10$ were removed from final models. Estimates for factors $( \pm S E)$ presented in text and tables are estimated marginal means (emmeans package: Lenth 2019) unless otherwise stated.

\section{Results}

\section{Resting metabolic rate}

Based on total RMR, LCT over both age groups was $14.2{ }^{\circ} \mathrm{C}$ (95\% CI 13.3-15.0 ${ }^{\circ} \mathrm{C}$ ) (Fig. 2a) and age-specific estimates of LCT were $14.2{ }^{\circ} \mathrm{C}\left(95 \% \mathrm{CI} 13.1-15.2{ }^{\circ} \mathrm{C}\right)$ and $14.3{ }^{\circ} \mathrm{C}\left(95 \% \mathrm{CI} 12.9-15.5{ }^{\circ} \mathrm{C}\right)$ for young and old birds, respectively. Below the overall LCT, RMR increased with $0.0093 \pm 0.0002 \mathrm{~W}$ for every $1{ }^{\circ} \mathrm{C}$ decrease in $T_{\mathrm{a}}$ $(P<0.0001$, Table 1, Fig. 2a). Young birds had a $6 \%$ higher RMR compared to old birds throughout the $T_{\mathrm{a}}$-range below LCT ( $P=0.013$, Table 1, Fig. 2a), but the difference between the age groups did not change with $T_{\mathrm{a}}\left(\right.$ age $\times T_{\mathrm{a}}$ 

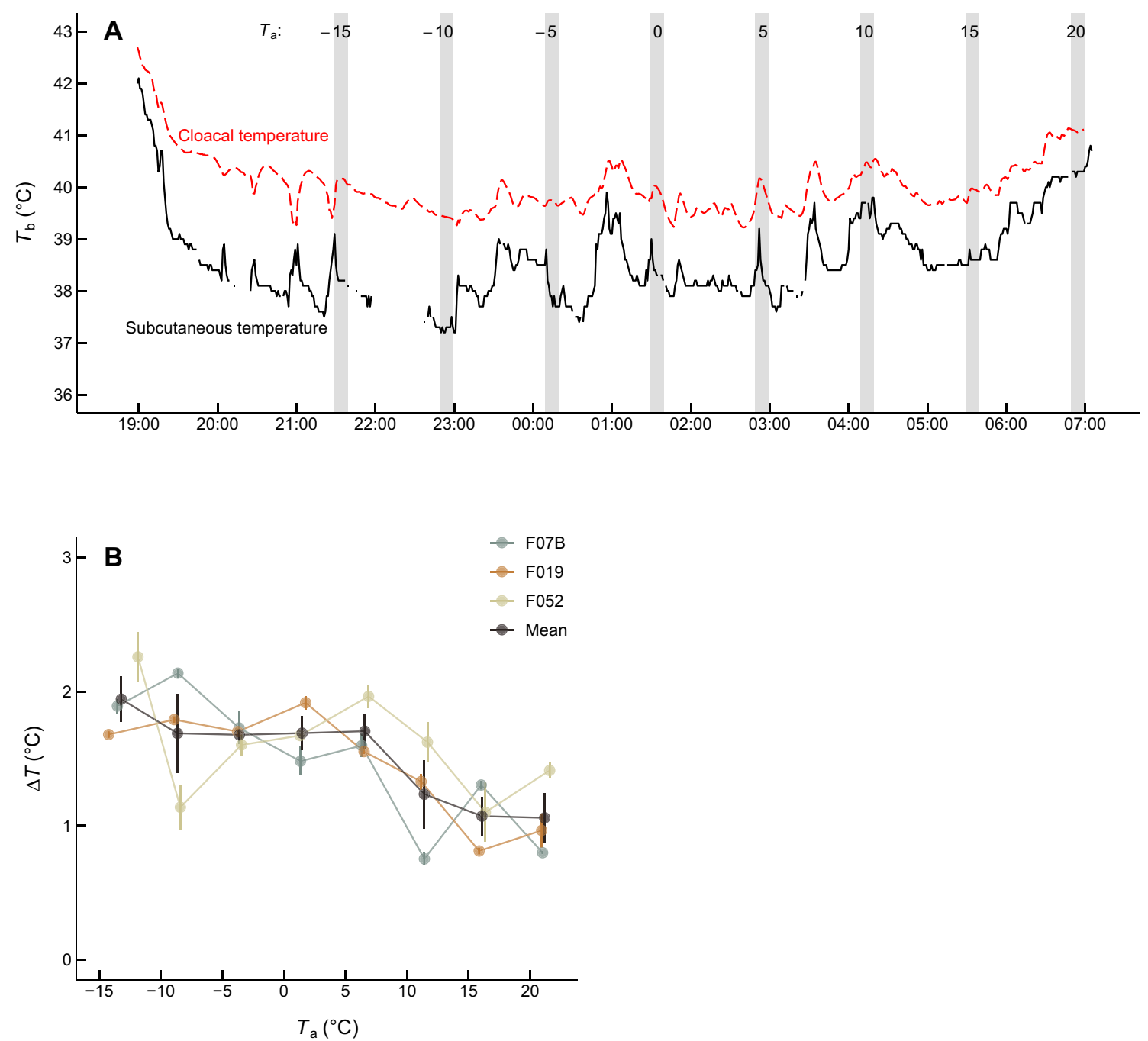

Fig. 1 a Example of $T_{\mathrm{b}}$ during a whole night of measurement, where $T_{\mathrm{b}}$ was continuously measured both subcutaneously (black), $T_{\mathrm{s}}$, and in the cloaca (red), $T_{\mathrm{c}}$. Grey bars indicate incremental increases in $T_{\mathrm{a}}$ and where data were extracted to create $\mathbf{b}$. b Mean $( \pm$ SE) difference,

interaction: $P=0.18)$. RMR above LCT (BMR) was also $7 \%$ higher in young birds compared to old birds $(P=0.028$, Table 1, Fig. 2a) and increased with increasing $T_{\mathrm{a}}(P=0.005$, Table 1, Fig. 2a). Body mass correlated positively with RMR, both below $(P=0.0002)$ and above $(P=0.003)$ LCT, and when body mass was accounted for, mass-adjusted RMR also tended to increase more with decreasing $T_{\mathrm{a}}$ in young birds compared to old birds (age $\times T_{\mathrm{a}}$ interaction: $P=0.054$, Fig. 2b, Table 1) below LCT. However, when body mass was accounted for, RMR above LCT did not differ between young and old birds $(P=0.13)$. Mean $( \pm S D)$ respiratory quotient across the whole $T_{\mathrm{a}}$ gradient was $0.715 \pm 0.005$, indicating that fat was the main substrate being catabolized during experiments (Fig. S1).
$\Delta T$, between subcutaneous temperature, $T_{\mathrm{s}}$, and cloacal temperature, $T_{\mathrm{c}}$, as a function of $T_{\mathrm{a}}$. Measurements are based on three individuals $(n=3)$ (color figure online)

\section{Subcutaneous and predicted body temperature}

Both $T_{\mathrm{s}}$ and predicted $T_{\mathrm{b}}$ showed a quadratic relationship with $T_{\mathrm{a}}$, where $T_{\mathrm{s}}$ and predicted $T_{\mathrm{b}}$ initially decreased as $T_{\mathrm{a}}$ decreased, but subsequently increased again at the lowest $T_{\text {a }}$ (Fig. 3). This effect was most pronounced in old birds, both for $T_{\mathrm{s}}\left(\right.$ age $\times T_{\mathrm{a}}{ }^{2}$ interaction $P=0.005$, Table 1, Fig. 3a) and for predicted $T_{\mathrm{b}}\left(\right.$ age $\times T_{\mathrm{a}}^{2}$ interaction $P=0.006$, Table 1 , Fig. 3b).

\section{Thermal conductance}

Overall, thermal conductance decreased with decreasing $T_{\mathrm{a}}$ below the LCT $(P<0.0001)$, was higher in young 

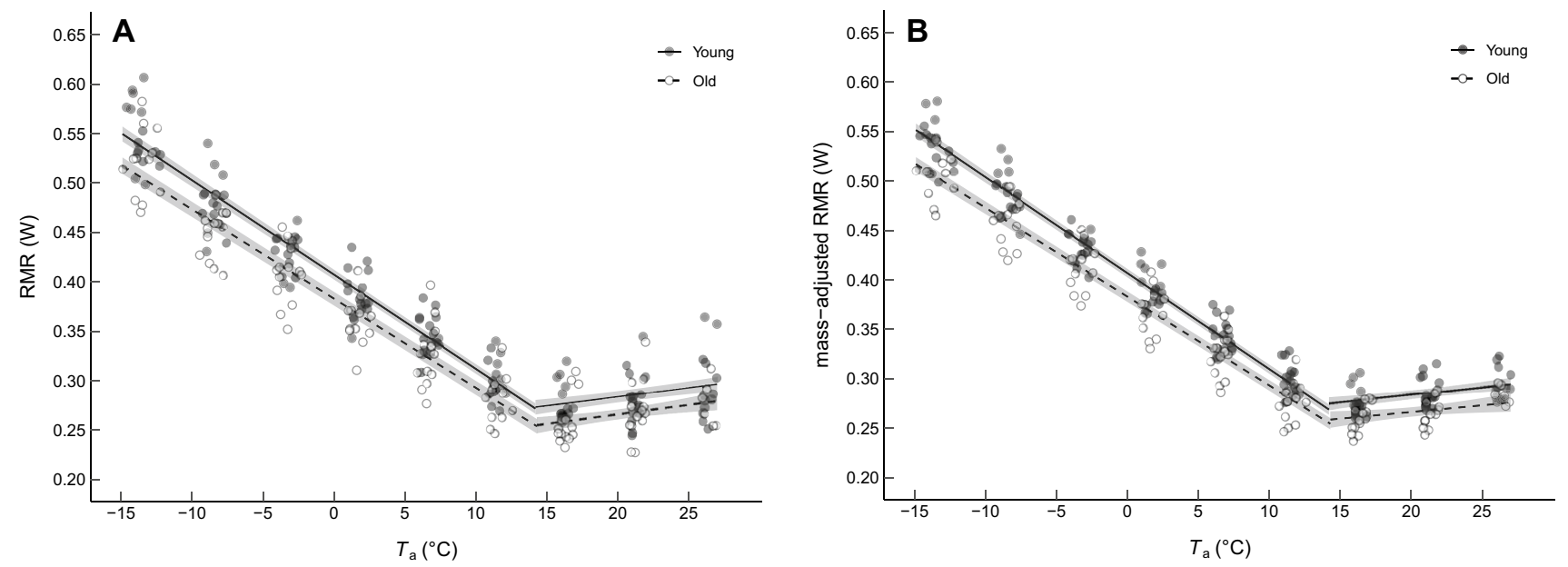

Fig. 2 a Whole animal resting metabolic rate (raw data) and $\mathbf{b}$ mass-adjusted resting metabolic rate (fitted values) in young and old blue tits as a function of $T_{\mathrm{a}}$. Age-specific regressions are model estimates $( \pm \mathrm{SE})$ from separate linear mixed models above and below LCT

birds $(P=0.012)$ and positively affected by body mass $(P=0.0001)$ (Fig. 4).

\section{Discussion}

Metabolic rate increased linearly below LCT. Mean ( \pm SD) resting metabolic rate above LCT (i.e. BMR, assuming a post-absorptive state) was $0.269 \pm 0.024 \mathrm{~W}$ across age groups which align well with previous studies in winter. For example, BMR reported here was $4 \%$ higher and $11 \%$ lower than BMR in blue tits previously measured in this population $\left(55^{\circ} \mathrm{N}\right)$ and in a more northerly population in Oulu, Finland $65^{\circ} \mathrm{N}$ ) (Broggi et al. 2019), and 6\% lower and 2\% higher compared to similar sized black-capped chickadees in South Dakota, USA ( $42^{\circ} \mathrm{N}$; Cooper and Swanson 1994) and in Quebec, Canada (48 ${ }^{\circ} \mathrm{N}$; Petit and Vézina 2014), respectively. $\mathrm{RMR}( \pm \mathrm{SD})$ at $-15^{\circ} \mathrm{C}$ was $0.536 \pm 0.036 \mathrm{~W}$ (i.e., twice that of BMR), suggesting that the blue tits in our experiment were far from using their full thermogenic capacity as summit metabolic rate $\left(M_{\text {sum }}\right.$ - maximum MR during cold exposure) usually range from 5 to $8 \times \mathrm{BMR}$ in other passerines (Dutenhoffer and Swanson 1996).

As predicted, young birds had a higher metabolic rate below thermoneutrality. This was accompanied by higher $T_{\mathrm{s}}$ and predicted $T_{\mathrm{b}}$. However, RMR above LCT was also higher in young birds and consequently LCT did not differ between the age groups. Using the mean predicted $T_{\mathrm{b}}$ above LCT $\left(39.4{ }^{\circ} \mathrm{C}\right)$ and mean evening body mass (12.1 g), predicted LCT for a resting blue tit is expected to be somewhere between $21.1{ }^{\circ} \mathrm{C}$ (Eq. 3 in Weathers and Van Riper 1982) and $25.9^{\circ} \mathrm{C}$ (Eq. 18 in Calder and King 1974). Thus, the observed value of $14.2{ }^{\circ} \mathrm{C}$ is well below allometric predictions. It is also lower than empirical data from similarly sized, phylogenetically related, black-capped chickadees in South Dakota $\left(18.3^{\circ} \mathrm{C}\right.$, Cooper and Swanson 1994), but aligns well with LCT in Alaskan black-capped chickadees (14.4 ${ }^{\circ} \mathrm{C}$, Grossman and West 1977) and redpolls Acanthis flammea $\left(11.5^{\circ} \mathrm{C}\right.$, Pohl and West 1973) which are naturally exposed to very low ambient temperatures.

In general, most birds did not reduce predicted $T_{\mathrm{b}}$ more than $4-5{ }^{\circ} \mathrm{C}$ from daytime levels (42.6 ${ }^{\circ} \mathrm{C}$ : Nord et al. 2009). Minimum predicted $T_{\mathrm{b}}( \pm \mathrm{SD})$ was attained when $T_{\mathrm{a}}$ was around $-5{ }^{\circ} \mathrm{C}$ and averaged $38.3 \pm 0.7{ }^{\circ} \mathrm{C}$ for young birds and $37.6 \pm 1.1^{\circ} \mathrm{C}$ for old birds. These measures of predicted $T_{\mathrm{b}}$ align well with previous studies of night-time hypothermia in undisturbed birds from the same population (Nord et al. 2009, 2011; 2013; Andreasson et al. 2019). A few individuals $(n=3)$ reduced $T_{\mathrm{s}}$ substantially to levels below $35^{\circ} \mathrm{C}$, but most birds exhibited a rather modest predicted $T_{\mathrm{b}}$ reduction over a $40{ }^{\circ} \mathrm{C}$ gradient from 25 to $-15^{\circ} \mathrm{C}$, with an initial decrease in $T_{\mathrm{s}}$ below LCT and a slight increase again at the lowest $T_{\mathrm{a}}$ (Fig. S2). Thus, for most birds, increased heat production below LCT was sufficient to maintain a relatively shallow hypothermic $T_{\mathrm{b}}$ with modest variation across the considered $T_{\mathrm{a}}$-range. It follows that the slight decrease in $T_{\mathrm{b}}$ below LCT might be a result of high heat loss rate (i.e., poor insulation) more than a reflection of change in set point.

Increased $T_{\mathrm{s}}$ and predicted $T_{\mathrm{b}}$ at the two coldest ambient temperatures was achieved without any detectable change in the rate of RMR increase. However, the ca. $1^{\circ} \mathrm{C}$ change in gradient between $T_{\mathrm{s}}$ and $T_{\mathrm{a}}$ would not necessarily be easily detected as a deviation from linearity in RMR. Nevertheless, increasing $T_{\mathrm{s}}$ in the two coldest temperatures suggests that the birds were able to further reduce heat loss and/or increase heat production. The fact that these processes were 
Table 1 Resting metabolic rate, body temperature, and thermal conductance in blue tits

\begin{tabular}{|c|c|c|c|c|}
\hline Variable & Estimate (SE) & $d f$ & $F / \chi^{2}$ & $P$ \\
\hline \multicolumn{5}{|l|}{ Total RMR $(W)$ below LCT } \\
\hline Age & & $1,28.2$ & 7.1 & 0.013 \\
\hline Young & $0.414(0.006)$ & & & \\
\hline Old & $0.392(0.006)$ & & & \\
\hline$T_{\mathrm{a}}$ & $-0.0093(0.0002)$ & $1,28.0$ & 2353.7 & $<0.0001$ \\
\hline ID (random intercept and slope) & & 3 & 89.8 & $<0.0001$ \\
\hline \multicolumn{5}{|l|}{ Mass-adjusted RMR (W) below LCT } \\
\hline Age & & $1,27.7$ & 7.3 & 0.012 \\
\hline Young & $0.413(0.005)$ & & & \\
\hline Old & $0.393(0.005)$ & & & \\
\hline$T_{\mathrm{a}}$ & $-0.0094(0.0002)$ & $1,27.2$ & 2504.7 & $<0.0001$ \\
\hline Age $\times T_{\mathrm{a}}$ & & $1,28.0$ & 4.1 & 0.054 \\
\hline Young $\times T_{\mathrm{a}}$ & $-0.0098(0.0003)$ & & & \\
\hline Old $\times T_{\mathrm{a}}$ & $-0.0090(0.0003)$ & & & \\
\hline Body mass & $0.015(0.004)$ & $1,32.4$ & 16.9 & 0.0002 \\
\hline ID (random intercept and slope) & & 3 & 57.3 & $<0.0001$ \\
\hline \multicolumn{5}{|l|}{ Total RMR (W) above LCT } \\
\hline Age & & $1,28.5$ & 5.4 & 0.028 \\
\hline Young & $0.285(0.005)$ & & & \\
\hline Old & $0.267(0.006)$ & & & \\
\hline$T_{\mathrm{a}}$ & $0.0018(0.0006)$ & $1,50.5$ & 8.5 & 0.005 \\
\hline ID (random intercept) & & 1 & 9.4 & 0.002 \\
\hline \multicolumn{5}{|l|}{ Mass-adjusted RMR (W) above LCT } \\
\hline Age & & $1,26.1$ & 2.4 & 0.13 \\
\hline$T_{\mathrm{a}}$ & $0.0015(0.0006)$ & $1,51.4$ & 5.5 & 0.023 \\
\hline Body mass & $0.012(0.004)$ & $1,28.0$ & 10.6 & 0.003 \\
\hline ID (random intercept) & & 1 & 4.3 & 0.037 \\
\hline \multicolumn{5}{|l|}{ Subcutaneous temperature, $T_{\mathrm{s}}\left({ }^{\circ} \mathrm{C}\right)$} \\
\hline Age & & $1,35.8$ & 7.6 & 0.009 \\
\hline$T_{\mathrm{a}}$ & & $1,26.9$ & 92.8 & $<0.0001$ \\
\hline$T_{\mathrm{a}}^{2}$ & & $1,194.5$ & 166.7 & $<0.0001$ \\
\hline Age $\times T_{\mathrm{a}}$ & & $1,26.9$ & 6.2 & 0.019 \\
\hline Age $\times T_{\mathrm{a}}^{2}$ & & $1,194.5$ & 8.2 & 0.005 \\
\hline Young $\times T_{\mathrm{a}}^{2}$ & $0.106(0.020)$ & & & \\
\hline $\operatorname{Old} \times T_{\mathrm{a}}^{2}$ & $0.179(0.021)$ & & & \\
\hline ID (random intercept and slope) & & 3 & 126.9 & $<0.0001$ \\
\hline \multicolumn{5}{|l|}{ Predicted body temperature, $T_{\mathrm{b}}\left({ }^{\circ} \mathrm{C}\right)$} \\
\hline Age & & $1,38.1$ & 7.8 & 0.008 \\
\hline$T_{\mathrm{a}}$ & & $1,29.5$ & 37.0 & $<0.0001$ \\
\hline$T_{\mathrm{a}}^{2}$ & & $1,169.4$ & 81.9 & $<0.0001$ \\
\hline Age $\times T_{\mathrm{a}}$ & & $1,29.5$ & 8.5 & 0.007 \\
\hline Age $\times T_{\mathrm{a}}^{2}$ & & $1,169.4$ & 7.8 & 0.006 \\
\hline Young $\times T_{\mathrm{a}}^{2}$ & $-0.005(0.003)$ & & & \\
\hline Old $\times T_{\mathrm{a}}^{2}$ & $-0.015(0.003)$ & & & \\
\hline ID (random) & & 3 & 104.9 & $<0.0001$ \\
\hline \multicolumn{5}{|l|}{ Conductance $\left(\mathrm{W}^{\circ} \mathrm{C}^{-1}\right)$} \\
\hline Age & & $1,28.2$ & 7.1 & 0.012 \\
\hline Young & $0.0110(0.0001)$ & & & \\
\hline Old & $0.0105(0.0001)$ & & & \\
\hline$T_{\mathrm{a}}$ & $3.5 e-05(4.3 e-06)$ & $1,29.9$ & 64.3 & $<0.0001$ \\
\hline ID (random) & & 3 & 75.7 & $<0.0001$ \\
\hline
\end{tabular}


Table 1 (continued)

\begin{tabular}{lllrr}
\hline Variable & Estimate $(\mathrm{SE})$ & $d f$ & $F / \chi^{2}$ & \multicolumn{1}{c}{$P$} \\
\hline Mass-adjusted conductance $\left(\mathrm{W}^{\circ} \mathrm{C}^{-1}\right)$ & & & & \\
$\quad$ Age & & $1,28.3$ & 6.4 & $\mathbf{0 . 0 1 7}$ \\
$\quad$ Young & $0.0109(0.0001)$ & & & \\
$\quad$ Old & $0.0106(0.0001)$ & & & \\
$T_{\text {a }}$ & $3.2 \mathrm{e}-05(4.1 \mathrm{e}-06)$ & $1,76.7$ & 61.3 & $<\mathbf{0 . 0 0 0 1}$ \\
Body mass & $0.0004(0.00009)$ & $1,36.1$ & 18.2 & $\mathbf{0 . 0 0 0 1}$ \\
ID (random) & & 3 & 48.8 & $<\mathbf{0 . 0 0 0 1}$ \\
\hline
\end{tabular}

Test statistics, degrees of freedom, parameter estimates, and levels of significance derived from linear mixed models on metabolic rate, body temperature, and thermal conductance in blue tits. For factors, estimates are least-square means (emmeans package; Lenth 2019). For continuous variables (and their interactions with factors), estimates represent the slope of the regression between the dependent variable and the continuous variable (SE represents the fit of the regression). Significant effects $(P<0.05)$ are given in bold and effects $0.05<P<0.1$ in italics
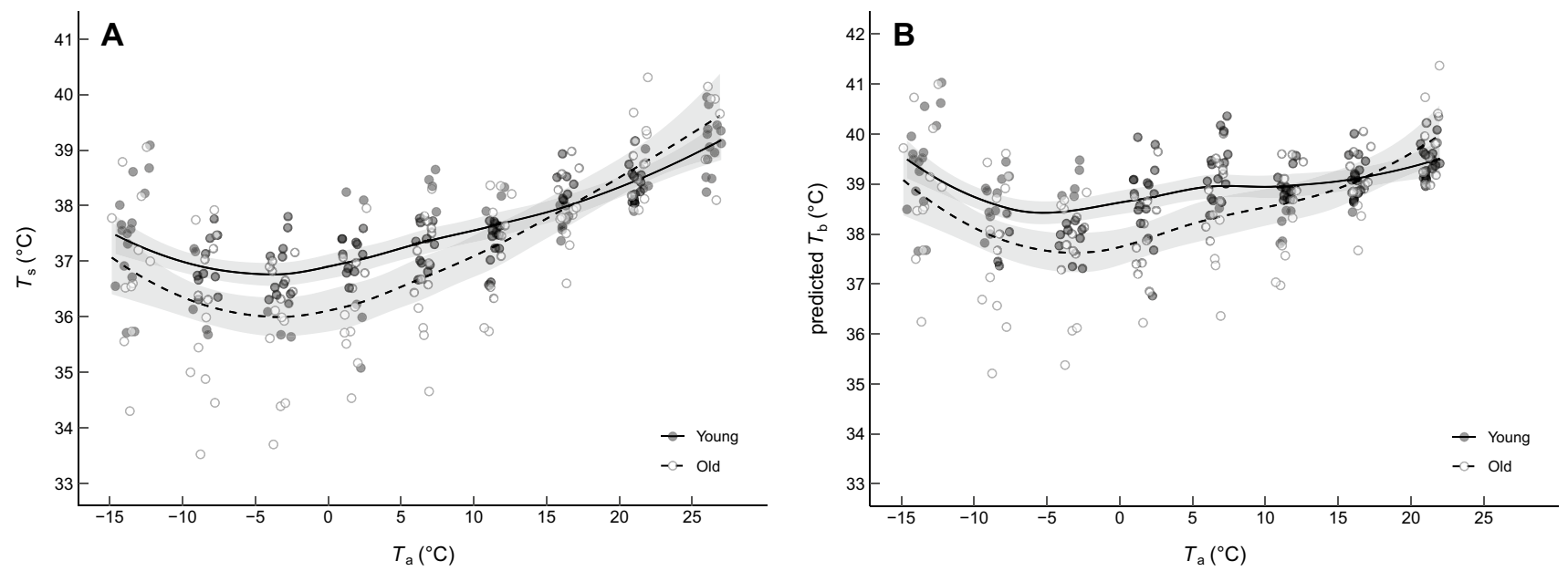

Fig. 3 a Subcutaneous body temperature, $T_{\mathrm{s}}$, and $\mathbf{b}$ predicted body temperature, $T_{\mathrm{b}}$, in young and old blue tits as a function of $T_{\mathrm{a}}$. Age-specific fitted curves are LOESS (locally estimated scatterplot smoothing) $\pm 95 \% \mathrm{CI}$

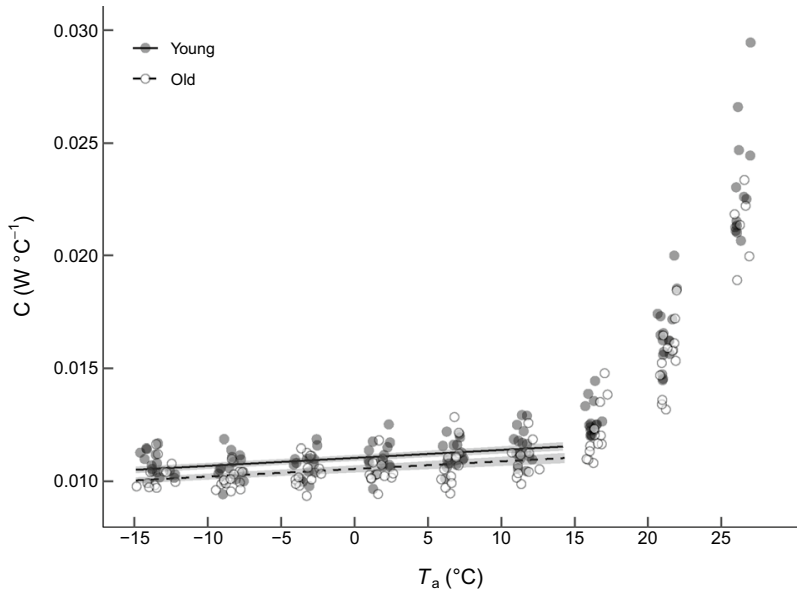

Fig. 4 Thermal conductance (raw data), $C$, in young and old blue tits as a function of $T_{\mathrm{a}}$. The regression line is an estimate $( \pm \mathrm{SE})$ from a linear mixed model below LCT not employed at milder $T_{\mathrm{a}}$ below LCT implies that they could be connected to costs. One possible route for heat loss reduction would be to further constrict peripheral blood flow to retain warm blood in the core. However, as $T_{\mathrm{s}}$ also increased at the lowest ambient temperatures, this mechanism at least did not involve the "shell" of the body. It is possible that some heat could be saved by reducing circulation to the head (which is a main avenue for heat loss in blue tits; Nord et al., unpublished data), at the expense of reduced vigilance and ensuing higher predation risk (Rashotte et al. 1998). Further reductions in peripheral circulation, or any other means to reduce heat loss rate, could also explain the slightly decreasing $C$ below LCT. Whether the increased $T_{\mathrm{s}}$ and predicted $T_{\mathrm{b}}$ at low $T_{\mathrm{a}}$ were related to further vasoconstriction of extremities, reduced circulation to the head region or other thermoregulatory responses (i.e.. recruitment of additional muscles for shivering thermogenesis: $\mathrm{cf}$. Saarela et al. 1995) requires further experimentation. 
So, why then, do young birds have a higher total RMR in the cold compared to old birds? Much of the variation in total RMR was explained by body mass, but young birds also tended to increase RMR more as $T_{\mathrm{a}}$ decreased compared to old birds when body mass was accounted for. One possible explanation could be differences in plumage quality, supported by the higher thermal conductance in young birds. It is worth noting that the biggest difference in mass-adjusted RMR between age groups occurred at the lowest $T_{\mathrm{a}},-15^{\circ} \mathrm{C}$, where the difference in $T_{\mathrm{s}}$ and predicted $T_{\mathrm{b}}$ between age groups was smallest. This could indicate that any inferior insulation in younger birds, caused e.g., by time or nutrient constraints during moult, needed to be compensated for by increased heat production, especially at low $T_{\mathrm{a}}$. Age-related differences in RMR could also be a consequence of a general decline in metabolic rate in older birds.

If young birds had to offset a higher heat loss with increased heat production to maintain $T_{\mathrm{b}}$ below thermoneutrality, we would expect $T_{\mathrm{b}}$ to be similar between age groups. So why do young birds maintain a higher body temperature in ambient temperatures below LCT compared to old birds? A similar difference between the age groups was found in the same blue tit population in response to increased perceived predation risk (Andreasson et al. 2019). As the confinement within a respirometer chamber may be experienced as a comparable stressor, it seems that young birds keep a higher body temperature in stressful environments. If this difference in $T_{\mathrm{b}}$ between age groups depends on senescence in thermogenic capacity, experience-based variation in risk assessment or variation in life history strategies (see Andreasson et al. 2019 for a discussion of these factors) or other, yet unidentified processes, needs to await further experimentation.

\section{Conclusions}

We have shown that metabolic rate in "the little bird in winter" follow a classic Scholander-Irving model (Scholander et al. 1950) where blue tits increase RMR linearly below the lower critical temperature, LCT $\left(14^{\circ} \mathrm{C}\right)$. Young birds had both higher RMR and $T_{\mathrm{b}}$ below the LCT compared to older conspecifics. Thermal conductance was also higher in young birds, indicating that they were producing more heat to offset increased heat loss compared to older birds. We believe that one likely explanation for this could be differences in plumage quality caused by time constraints during moult. $T_{\mathrm{b}}$ reduction was moderate $\left(4-5{ }^{\circ} \mathrm{C}\right.$ reduction from day time levels), though predicted $T_{\mathrm{b}}$ and $T_{\mathrm{s}}$ decreased below LCT and increased again at the coldest $T_{\text {a. }}$ These changes were likely reflections of high heat loss rate, potentially coupled to additional thermoregulatory responses to conserve heat at the lowest $T_{\mathrm{a}}$. This implies that rest-phase hypothermia in tits might be mechanistically different compared to species with the capacity for deeper torpor (e.g., swifts, nightjars, and hummingbirds: McKechnie and Lovegrove 2002). Future studies should look to more explicitly evaluate variation in plumage quality and thermal conductivity of plumage between age groups, and how this might affect $T_{\mathrm{b}}$ and RMR. This could help pinpoint mechanisms responsible for the relation between RMR and $T_{\mathrm{b}}$ at cold ambient temperatures.

Acknowledgements Open access funding provided by Lund University. We would like to thank Johan Nilsson for helping with setting up the respirometry equipment and Joost de Jong for help with fieldwork. This work was supported by Stiftelsen Lunds Djurskyddsfond (to FA), the Swedish Research Council (637-2013-7442 to AN, 2016-04240 to J-ÅN), the Birgit and Hellmuth Hertz Foundation/the Royal Physiographic Society of Lund (2017-39034 to AN).

Author contribution FA, AN, and JAN conceived the ideas; FA, AN, and JÅN designed methodology; FA collected and analyzed the data, and led the writing of the manuscript together with all authors. All authors contributed critically to the drafts and gave final approval for publication.

Data availability Data is attached as supplementary material in the online version of this article.

\section{Compliance with ethical standards}

Conflict of interest The authors declare that they have no conflict of interest.

Ethical approval All applicable institutional and national guidelines for the care and use of animals were followed.

Open Access This article is licensed under a Creative Commons Attribution 4.0 International License, which permits use, sharing, adaptation, distribution and reproduction in any medium or format, as long as you give appropriate credit to the original author(s) and the source, provide a link to the Creative Commons licence, and indicate if changes were made. The images or other third party material in this article are included in the article's Creative Commons licence, unless indicated otherwise in a credit line to the material. If material is not included in the article's Creative Commons licence and your intended use is not permitted by statutory regulation or exceeds the permitted use, you will need to obtain permission directly from the copyright holder. To view a copy of this licence, visit http://creativecommons.org/licenses/by/4.0/.

\section{References}

Andreasson F, Nord A, Nilsson J-Å (2019) Age-dependent effects of predation risk on night-time hypothermia in two wintering passerine birds. Oecologia 189:329-337

Aschoff J (1981) Thermal conductance in mammals and birds: Its dependence on body size and circadian phase. Comp Biochem Physiol A 69:611-619

Bates D, Mäechler M, Bolker B, Walker S (2015) Fitting linear mixed effects models using lme4. J Stat Soft 67:1-48

Brodin A (2007) Theoretical models of adaptive energy management in small wintering birds. Philos Trans R Soc Lond B 362:1857-1871 
Brodin A, Nilsson JÅ, Nord A (2017) Adaptive temperature regulation in the little bird in winter: predictions from a stochastic dynamic programming model. Oecologia 185:43-54

Broggi J, Gamero A, Hohtola E, Orell M, Nilsson JÅ (2011) Interpopulation variation in contour feather structure is environmentally determined in great tits. PLoS ONE 6:e24942

Broggi J, Nilsson JF, Koivula K, Hohtola E, Nilsson JÅ (2019) Mass or pace? Seasonal energy management in wintering boreal passerines. Oecologia 189:339-351

Calder WA, King JR (1974) Thermal and caloric relations of birds. In: Farner DS, King JR (eds) Avian biology, vol 4. Academic Press, New York, pp 259-413

Carr JM, Lima SL (2013) Nocturnal hypothermia impairs flight ability in birds: a cost of being cool. Proc R Soc B 280:20131846

Chaplin SB (1976) The physiology of hypothermia in the black-capped chickadee, Parus atricapillus. J Comp Physiol 112:335-344

Cooper SJ (2002) Seasonal metabolic acclimatization in mountain chickadees and juniper titmice. Physiol Biochem Zool 74:386-395

Cooper SJ, Gessaman JA (2005) Nocturnal hypothermia in seasonally acclimatized mountain chickadees and juniper titmice. Condor 107:151-155

Cooper SJ, Swanson DL (1994) Seasonal acclimatization of thermoregulation in the black-capped chickadee. Condor 96:638-646

Dawson WR, Carey C (1976) Seasonal acclimatization to temperature in cardueline finches. I. insulative and metabolic adjustments. J Comp Physiol 112:317-333

Dolby AS, Temple JG, Williams LE, Dilger EK, Stechler KM, Davis VS (2004) Facultative rest-phase hypothermia in free-ranging white-throated sparrows. Condor 106:386-390

Du Plessis MA, Williams JB (1994) Communal cavity roosting in green woodhoopoes: consequences for energy expenditure and the seasonal pattern of mortality. Auk 111:292-299

Duchamp C, Barre H (1993) Skeletal muscle as the major site of nonshivering thermogenesis in cold-acclimated ducklings. Am J Physiol 265:R1076-R1083

Duchamp C, Cohen-Adad F, Rouanet JL, Barré H (1992) Histochemical arguments for muscular nonshivering thermogenesis in muscovy ducklings. J Physiol 457:27-45

Dutenhoffer MS, Swanson DL (1996) Relationship of basal to summit metabolic rate in passerine birds and the aerobic capacity model for the evolution of endothermy. Physiol Zool 69:1232-1254

Elkins N (2004) Weather and bird behaviour. T \& AD Poyser, London

Ginn HB, Melville DS (1983) Moult in birds. BTO, Tring

Grossman AF, West GC (1977) Metabolic rate and temperature regulation of winter acclimatized black-capped chickadees Parus atricapillus in interior Alaska. Ornis Scand 88:127-138

Haftorn S (1992) The diurnal body weight cycle in titmice Parus spp. Orn Scand 23:435-443

Hayes JP (2001) Mass specific and whole-animal metabolism are not the same concept. Physiol Biochem Zool 74:147-150

Hill RW, Beaver DL, Veghte JH (1980) Body surface temperatures and thermoregulation in the black-capped chickadee (Parus atricapillus). Physiol Zool 53:305-321

Hohtola E (2004) Shivering thermogenesis in birds and mammals. In: Barnes BM, Carey HV (eds) Life in the cold: evolution, mechanisms, adaptation, and application. 12th international hibernation symposium. Biological papers, University of Alaska \#27. Institute of Arctic Biology, University of Alaska, Fairbanks, pp 241-252

Hohtola E, Rintamäki H, Hissa R (1980) Shivering and ptiloerection as complementary cold defense responses in the pigeon during sleep and wakefulness. J Comp Physiol 136:77-81

Kleiber M (1961) The fire of life. Wiley, New York

Laurila M, Hohtola E (2005) The effect of ambient temperature and simulated predation risk on fasting-induced nocturnal hypothermia of pigeons in outdoor conditions. J Therm Biol 30:392-399
Lenth R (2019) emmeans: estimated marginal means, aka least-squares means. R package version 1.3.2. https://CRAN.R-project.org/ package $=$ emmeans

Lighton JRB (2008) Measuring metabolic rates-a manual for scientists. Oxford University Press, New York

Marsh RL, Dawson WR (1989) Avian adjustments to cold. In: Wang LCH (ed) Advances in comparative and environmental physiology 4: animal adaptation to cold. Springer, Berlin, pp 206-253

McKechnie AE, Lovegrove BG (2002) Avian facultative hypothermic responses: a review. Condor 104:705-724

Mueller JC, Steinmeyer C, Kempenaers B (2012) Individual variation in sleep-wake rhythms in free-living birds. Chronobiol Int 29:1216-1226

Nilsson JÅ, Svensson E (1996) The cost of reproduction: a new link between current reproductive effort and future reproductive success. Proc R Soc B 263:711-714. https://doi.org/10.1098/ rspb.1996.0106

Nord A, Folkow LP (2018) Seasonal variation in the thermal responses to changing environmental temperature in the world's northernmost land bird. J Exp Biol 221:jeb171124

Nord A, Nilsson JF, Sandell MI, Nilsson JA (2009) Patterns and dynamics of rest-phase hypothermia in wild and captive blue tits during winter. J Comp Physiol B 179:737-745

Nord A, Nilsson JF, Nilsson JÅ (2011) Nocturnal body temperature in wintering blue tits is affected by roost-site temperature and body reserves. Oecologia 167:21-25

Nord A, Sköld-Chiriac S, Hasselquist D, Nilsson JÅ (2013) Endotoxin injection attenuates rest-phase hypothermia in wintering great tits through the onset of fever. Funct Ecol 27:236-244

Osváth G, Daubner T, Dyke G et al (2018) How feathered are birds? Environment predicts both the mass and density of body feathers. Funct Ecol 32:701-712

Packard GC, Boardman TJ (1999) The use of percent-ages and size specific indices to normalise physiological data for variation in body size: wasted time, wasted effort? Comp Biochem Physiol A 122:37-44

Palmgren P (1944) Körpertemperatur und Wärmeschutz bei einigen finnischen Vögeln. Ornis Fenn 21:99-104

Pap PL, Vincze O, Wekerle B, Daubner T, Vágási CI, Nudds RL, Dyke GJ, Osváth G (2017) A phylogenetic comparative analysis reveals correlations between body feather structure and habitat. Funct Ecol 31:1241-1251

Petit M, Vézina F (2014) Reaction norms in natural conditions: how does metabolic performance respond to weather variations in a small endotherm facing cold environments? PLoS ONE 9(11):e113617

Pohl H, West GC (1973) Daily and seasonal variation in metabolic response to cold during rest and forced exercise in the common redpoll. Comp Biochem Physiol 45A:851-867

Rashotte ME, Pastukhov IF, Poliakov EL, Henderson RP (1998) Vigilance states and body temperature during the circadian cycle in fed and fasted pigeons (Columba livia). Am J Physiol Regul Integr Comp Physiol 275:R1690-R1702

R Development Core Team (2018) R: a language and environment for statistical computing. R Foundation for Statistical Computing, Vienna

Reinertsen RE, Haftorn S (1983) Nocturnal hypothermia and metabolism in the willow tit Parus montanus at $63^{\circ}$ N. J Comp Physiol 151:109-118

Reinertsen RE, Haftorn S (1984) The effect of short-time fasting on the metabolism and nocturnal hypothermia in the willow tit Parus montanus. J Comp Physiol B 154:23-28

Reinertsen RE, Haftorn S (1986) Different metabolic strategies of northern birds for nocturnal survival. J Comp Physiol 156:655-663 
Saarela S, Klapper B, Heldmaier G (1995) Daily rhythm of oxygen consumption and thermoregulatory responses in some European winter- or summer-acclimatized finches at different ambient temperatures. J Comp Physiol B 165:366-376

Scholander PF, Hock R, Walters V, Johnson F, Irving L (1950) Heat regulation in some Arctic and tropical mammals and birds. Biol Bull 99:237-258

Sköld-Chiriac S, Nord A, Nilsson JÅ, Hasselquist D (2015) Body temperature changes during simulated bacterial infection in a songbird: fever at night and hypothermia during the day. J Exp Biol 218:2961-2969

Smith HG, Nilsson JÅ (1987) Intraspecific variation in migratory pattern of a partial migrant, the blue tit (Parus caeruleus): an evaluation of different hypotheses. Auk 104:109-115

Steen JB (1958) Climatic adaptation in some small northern birds. Ecology 39:625-629

Svensson L (1992) Identification guide to European passerines. British Trust for Ornithology, Norfolk

Svensson E, Nilsson JA (1997) The trade-off between molt and parental care: a sexual conflict in the blue tit? Behav Ecol 8:92-98

Swanson DL (1991) Seasonal adjustments in metabolism and insulation in the dark-eyed junco. Condor 93:538-545
Teulier L, Rouanet JL, Letexier D, Romestaing C, Belouze M, Rey B, Duchamp C, Roussel D (2010) Cold-acclimation-induced nonshivering thermogenesis in birds is associated with upregulation of avian UCP but not with innate uncoupling or altered ATP efficiency. J Exp Biol 213:2476-2482

Udvardy MDF (1955) Body temperature of parids in the arctic winter. Ornis Fenn 32:101-107

Vágási CI, Pap PL, Vincze O, Benkő Z, Marton A, Barta Z (2012) Haste makes waste but condition matters: molt rate-feather quality trade-off in a sedentary songbird. PLoS ONE 7:e40651

Weathers W, Van Riper C (1982) Temperature regulation in two endangered Hawaiian honeycreepers: the Palila (Psittirostra bailleui) and the Laysan finch (Psittirostra cantans). Auk 99:667-674

Publisher's Note Springer Nature remains neutral with regard to jurisdictional claims in published maps and institutional affiliations. 